OPEN ACCESS

Edited by:

Nicola Fusco,

University of Milan, Italy

Reviewed by:

Alberto Concardi,

European Institute of Oncology (IEO),

Italy

Peter Gibbs,

Memorial Hospital, United States

*Correspondence:

Hailin Shen

hailinshen@163.com

${ }^{t}$ These authors have contributed equally to this work and share

first authorship

Specialty section: This article was submitted to Breast Cancer,

a section of the journal

Frontiers in Oncology

Received: 16 December 2021 Accepted: 07 February 2022

Published: 01 March 2022

Citation:

Li Z, Ye J, Du H, Cao Y, Wang Y, Liu D, Zhu F and Shen H (2022)

Preoperative Prediction Power of

Radiomics for Breast Cancer: A Systemic Review and Meta-Analysis.

Front. Oncol. 12:837257.

doi: 10.3389/fonc.2022.837257

\section{Preoperative Prediction Power of Radiomics for Breast Cancer: A Systemic Review and Meta-Analysis}

\author{
Zhenkai $\mathrm{Li}^{1 \dagger}$, Juan Ye ${ }^{1 \dagger}$, Hongdi Du ${ }^{1}$, Ying Cao ${ }^{2}$, Ying Wang ${ }^{1}$, Desen $\mathrm{Liu}^{3}$, \\ Feng Zhu ${ }^{1}$ and Hailin Shen ${ }^{1 *}$ \\ ${ }^{1}$ Department of Radiology, Suzhou Kowloon Hospital, Shanghai Jiaotong University School of Medicine, Suzhou, China, \\ 2 Department of Radiotherapy, Suzhou Kowloon Hospital, Shanghai Jiaotong University School of Medicine, Suzhou, China, \\ ${ }^{3}$ Department of Thoracic Surgery, Suzhou Kowloon Hospital, Shanghai Jiaotong University School of Medicine, \\ Suzhou, China
}

Background: To evaluate the preoperative predictive value of radiomics in the diagnosis of breast cancer $(\mathrm{BC})$.

Methods: By searching PubMed and Embase libraries, our study identified 19 eligible studies. We conducted a meta-analysis to assess the differential value in the preoperative assessment of $\mathrm{BC}$ using radiomics methods.

Results: Nineteen radiomics studies focusing on the diagnostic efficacy of BC and involving 5865 patients were enrolled. The integrated sensitivity and specificity were 0.84 (95\% Cl: $\left.0.80-0.87, l^{2}=76.44 \%\right)$ and 0.83 (95\% Cl: 0.78-0.87, $\left.I^{2}=81.79 \%\right)$, respectively. The AUC based on the SROC curve was 0.91, indicating a high diagnostic value.

Conclusion: Radiomics has shown excellent diagnostic performance in the preoperative prediction of $\mathrm{BC}$ and is expected to be a promising method in clinical practice.

Keywords: breast cancer, radiomics, cancer prediction, meta-analysis, systematic review

\section{INTRODUCTION}

Breast cancer $(\mathrm{BC})$ is the most commonly diagnosed cancer among women, accounting for $23 \%$ of all female cancers worldwide, and its related mortality is increasing by $4 \%$ each year (1). Traditional screening methods for BC, including X-ray mammography (MMG), breast ultrasound (US), and breast magnetic resonance imaging (MRI), rely mainly on qualitative characteristics, such as the lesion density, shape of lesion margins, and enhancement pattern. These imaging methods for BC screening have limitations in the sensitivity and specificity of diagnosis. As a result, biopsies are often performed to provide a definitive diagnosis for the patient. In the era of precision medicine, improvements in the performance of $\mathrm{BC}$ detection are urgently needed to reduce unnecessary

\footnotetext{
Abbreviations: BC, Breast cancer; CI, Confidence interval; ROC, Receiver operating characteristic; SROC, Summary receiver operating characteristic; AUC, Area under curve; MMG, Mammography; US, Ultrasound; MRI, Magnetic Resonance Imaging; TP, True positive; FP, False positive; TN, True negative; FN, False negative; RA, Radiomics algorithm; ML, Machine learning; DL, Deep learning; BI-RADS, Breast Imaging Reporting and Data System; DWI, Diffusion-weighted imaging; DCE, Dynamic contrast-enhanced.
} 
biopsies, which are invasive and painful. Radiomics is an emerging application that can extract innumerable quantitative image features (including descriptors of tumor shape, size, intensity, and texture) that are difficult to recognize with the naked eye from almost any medical image (2). The traditional imaging diagnostic mode is more dependent on the experience of radiologists and has strong subjectivity. Compared with traditional imaging diagnosis mode, radiomics is an emerging application that can extract innumerable quantitative image features (including descriptors of tumor shape, size, intensity, and texture) that are difficult to recognize with the naked eye from almost any medical image (2). These image features may be related to the microscopic structure and tissue biological information of tumors. Based on this, combined with clinical, pathological and genetic information, the imaging support system for clinical decision making can be constructed. A number of studies have shown that the radiomics model can improve the accuracy of breast cancer diagnosis by extracting texture features of lesion and contralateral normal breast respectively and constructing benign/malignant classifiers $(3,4)$. Radiomics features have proven to be of significant value in differentiating between benign and malignant breast tumors $(5,6)$. Therefore, radiomics provides a promising method for improving the sensitivity and specificity of the diagnosis of BCs. By refining BC detection, radiomics has the potential to reduce unnecessary invasive biopsies. In addition, Shimauchi et al. (7) found that the performance of radiologists during diagnostic tasks improved when a computer-aided diagnosis system was used. Hence, the purpose of this study was to evaluate the diagnostic efficacy of radiomics in predicting $\mathrm{BC}$.

\section{MATERIALS AND METHODS}

\section{Literature Retrieving}

PubMed and EMBASE databases were comprehensively searched by two reviewers (L-ZK and YJ) using the following keywords: radiomics and $\mathrm{BC}$, breast carcinoma, breast tumor, or breast neoplasm. The deadline of this retrieval was September 10, 2021. Two reviewers independently screened the abstracts of all manuscripts, and full publications were downloaded when the decision of including an article was ambiguous. Discussion was conducted to resolve disagreements on article inclusion. The reference lists of eligible studies were also searched for potential additional studies.

\section{Selection Criteria}

The inclusion criteria were as follows: (1) diagnosis of BC on the basis of pathologic criteria; (2) breast imaging, including US, MRI, and/or digital MMG, was performed before biopsy or resection; and (3) radiomics analysis based on breast images was conducted.

The exclusion criteria were as follows: (1) preoperative administration of anticancer therapy (chemotherapy or radiotherapy); (2) the pathological diagnosis was not clear; and (3) imaging analysis based only on non-radiomics methods.

\section{Data Extraction and Study Quality Assessment}

Two investigators (L-ZK and YJ) independently extracted the number of $\mathrm{BC}$ and non-BC cases, sensitivity, and specificity reported in the eligible studies. Using these data, we calculated the number of true positive (TP), false positive (FP), true negative (TN), and false negative $(\mathrm{FN})$ results. If there were more than one model in the same group of patients, we used the model with the higher diagnostic accuracy in our meta-analysis. All studies included were quality assessed using the QUADAS-2 scale (8) in Revman 5.5 (Cochrane Library Software, Oxford, UK).

\section{Statistical Analysis}

The pooled sensitivity and specificity were estimated. We also calculated pooled positive and negative likelihood ratios. Heterogeneity between the included studies was assessed by Cochrane's Q-test and $I^{2}$ statistics. The summary receiver operating characteristic (SROC) curve and the area under the SROC curve (AUC) were also constructed to evaluate the diagnostic value of combined studies (9). AUCs of 0.5-0.7 indicated low diagnostic power, AUCs of 0.7-0.9 indicated moderate diagnostic power, and AUCs of 0.9-1.0 indicated high diagnostic power $(10,11)$. All statistical analyses were performed using Stata version 15.0 (Stata Corp), and $P<0.05$ was considered statistically significant.

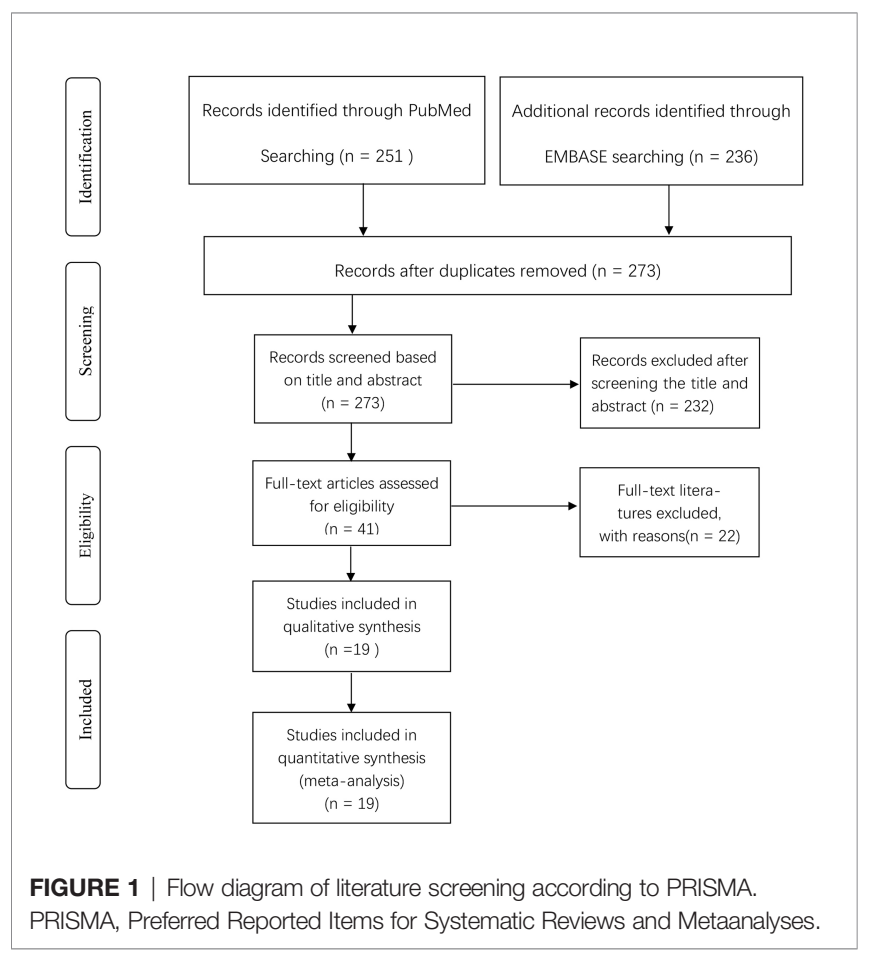




\section{RESULTS}

\section{Literature Selection and Quality Assessment}

Details of the selection procedure are shown in Figure 1. After the removal of duplicate articles, we reviewed the abstracts of 219 articles identified in the initial review. Nineteen eligible studies involving 5865 patients were included (12-30). Among them, 3500 patients were pathologically diagnosed with BC and 2365 patients as non-BC. The basic characteristics of all eligible studies are displayed in Table $\mathbf{1}$, and the quality assessment of all included studies based on the QUADAS-2 scale is shown in Figure 2.

\section{Radiomics for the Preoperative Prediction of BC}

A total of 5865 patients, comprising 3500 BC and 2365 non-BC patients, were assessed using a radiomics method. Figure 3 shows the forest plots of the diagnostic meta-analysis and combined results. The integrated sensitivity and specificity were 0.84 (95\% CI: $\left.0.80-0.87, I^{2}=76.44 \%\right)$ and 0.83 (95\% CI: $\left.0.78-0.87, I^{2}=81.79 \%\right)$, respectively. The AUC based on the SROC curve was 0.91 (Figure 4), demonstrating a high diagnostic value.

\section{Subgroup Analyses and Sensitivity Analyses}

Subgroup analyses were performed and included five different conditions and eleven subgroups. Radiomics models showed moderate to high diagnostic value in each subgroup of imaging modalities (MMG, US, and MRI), study design (prospective and retrospective), data source (China and America), modeling method [Radiomics algorithm (RA), machine learning (ML), and deep learning (DL)]. Both conventional and functional imaging analyses provided a high diagnostic accuracy of BC. The results are displayed in Table 2 . Repeating the meta-analyses

TABLE 1 | Basic characteristics.

\begin{tabular}{|c|c|c|c|c|c|c|c|c|c|c|c|c|c|}
\hline Study & $\begin{array}{l}\text { Study } \\
\text { Design }\end{array}$ & Region & No. & $\begin{array}{l}\text { Radiomics } \\
\text { algorithm }\end{array}$ & Subgroup & $\begin{array}{l}\text { Imaging } \\
\text { modality }\end{array}$ & BC & $\begin{array}{l}\text { non- } \\
\text { BC }\end{array}$ & TP & FP & $\mathbf{F N}$ & TN & Feature type \\
\hline $\begin{array}{l}\text { Zhang,2017 } \\
\text { (28) }\end{array}$ & Retrospective & China & 117 & $\begin{array}{l}\text { Conventional } \\
\text { algorithm }\end{array}$ & $\begin{array}{l}\text { Conventional } \\
\text { image }\end{array}$ & US & 42 & 75 & 36 & 8 & 6 & 67 & 7 radiomic features \\
\hline $\mathrm{Hu}, 2018$ (15) & Retrospective & China & 88 & Machine learning & $\begin{array}{l}\text { Functional } \\
\text { image }\end{array}$ & $\mathrm{MRI}$ & 52 & 36 & 42 & 8 & 10 & 28 & 5 radiomic features \\
\hline Luo,2019 (21) & Retrospective & China & 315 & $\begin{array}{l}\text { Conventional } \\
\text { algorithm }\end{array}$ & $\begin{array}{l}\text { Conventional } \\
\text { image }\end{array}$ & US & $\begin{array}{l}68 \\
35\end{array}$ & $\begin{array}{c}143 \\
69\end{array}$ & $\begin{array}{l}52 \\
29\end{array}$ & $\begin{array}{c}24 \\
5\end{array}$ & $\begin{array}{l}16 \\
6\end{array}$ & $\begin{array}{c}119 \\
64\end{array}$ & 9 radiomic features \\
\hline Li,2019 (19) & Retrospective & USA & 182 & $\begin{array}{l}\text { Conventional } \\
\text { algorithm }\end{array}$ & $\begin{array}{l}\text { Conventional } \\
\text { image }\end{array}$ & MMG & 106 & 76 & 83 & 18 & 23 & 58 & 32 radiomic features \\
\hline $\begin{array}{l}\text { Drukker,2019 } \\
\text { (13) }\end{array}$ & Prospective & USA & 109 & $\begin{array}{l}\text { Conventional } \\
\text { algorithm }\end{array}$ & $\begin{array}{l}\text { Conventional } \\
\text { image }\end{array}$ & MMG & 35 & 74 & 34 & 36 & 1 & 38 & 9 radiomic features \\
\hline $\begin{array}{l}\text { Whitney,2019 } \\
\text { (27) }\end{array}$ & Retrospective & USA & 462 & Deep learning & $\begin{array}{l}\text { Functional } \\
\text { image }\end{array}$ & $\mathrm{MRI}$ & 296 & 212 & 222 & 46 & 74 & 166 & 38 radiomic features \\
\hline Ji,2019 (17) & Retrospective & China & 1979 & Machine learning & $\begin{array}{l}\text { Functional } \\
\text { image }\end{array}$ & $\mathrm{MRI}$ & 421 & 114 & 352 & 20 & 69 & 94 & 10 radiomic features \\
\hline $\begin{array}{l}\text { Gibbs,2019 } \\
(14)\end{array}$ & Retrospective & USA & 149 & $\begin{array}{l}\text { Conventional } \\
\text { algorithm }\end{array}$ & $\begin{array}{l}\text { Functional } \\
\text { image }\end{array}$ & $\mathrm{MRI}$ & 9 & 32 & 6 & 0 & 3 & 32 & $\begin{array}{l}4 \text { Clinical and } 1 \text { radiomics } \\
\text { feature }\end{array}$ \\
\hline $\begin{array}{l}\text { Chen,2019 } \\
(12)\end{array}$ & Retrospective & China & 81 & $\begin{array}{l}\text { Conventional } \\
\text { algorithm }\end{array}$ & $\begin{array}{l}\text { Functional } \\
\text { image }\end{array}$ & MMG, MRI & 40 & 41 & 33 & 8 & 7 & 33 & 14 radiomic features \\
\hline $\begin{array}{l}\text { Truhn, } 2019 \\
\text { (26) }\end{array}$ & Retrospective & Germany & 447 & $\begin{array}{l}\text { Conventional } \\
\text { algorithm }\end{array}$ & $\begin{array}{l}\text { Functional } \\
\text { image }\end{array}$ & $\mathrm{MRI}$ & 787 & 507 & 616 & 78 & 171 & 429 & 10 radiomic features \\
\hline Lei, 2019 (18) & Retrospective & China & 419 & $\begin{array}{l}\text { Conventional } \\
\text { algorithm }\end{array}$ & $\begin{array}{l}\text { Conventional } \\
\text { image }\end{array}$ & MMG & $\begin{array}{l}78 \\
28\end{array}$ & $\begin{array}{l}81 \\
25\end{array}$ & $\begin{array}{l}63 \\
25\end{array}$ & $\begin{array}{c}18 \\
9\end{array}$ & $\begin{array}{c}15 \\
3\end{array}$ & $\begin{array}{l}63 \\
16\end{array}$ & 6 radiomic features \\
\hline $\begin{array}{l}\text { Mao, } 2019 \\
(22)\end{array}$ & Retrospective & China & 173 & $\begin{array}{l}\text { Conventional } \\
\text { algorithm }\end{array}$ & $\begin{array}{l}\text { Conventional } \\
\text { image }\end{array}$ & MMG & $\begin{array}{l}79 \\
20\end{array}$ & $\begin{array}{l}59 \\
15\end{array}$ & $\begin{array}{l}78 \\
17\end{array}$ & $\begin{array}{l}1 \\
1\end{array}$ & $\begin{array}{l}1 \\
3\end{array}$ & $\begin{array}{l}58 \\
14\end{array}$ & 51 radiomic features \\
\hline $\begin{array}{l}\text { Gullo,2020 } \\
(20)\end{array}$ & Retrospective & USA & 430 & $\begin{array}{l}\text { Conventional } \\
\text { algorithm }\end{array}$ & $\begin{array}{l}\text { Functional } \\
\text { image }\end{array}$ & $\mathrm{MRI}$ & 40 & 76 & 25 & 7 & 15 & 69 & $\begin{array}{l}1 \text { Clinical and } 10 \text { radiomics } \\
\text { features }\end{array}$ \\
\hline $\mathrm{Hu}, 2020(16)$ & Retrospective & USA & 612 & $\begin{array}{l}\text { Conventional } \\
\text { algorithm }\end{array}$ & $\begin{array}{l}\text { Functional } \\
\text { image }\end{array}$ & $\mathrm{MRI}$ & 657 & 159 & 520 & 36 & 137 & 123 & 75 radiomic features \\
\hline $\begin{array}{l}\text { Parekh,2020 } \\
\text { (23) }\end{array}$ & Retrospective & USA & 138 & $\begin{array}{l}\text { Conventional } \\
\text { algorithm }\end{array}$ & $\begin{array}{l}\text { Functional } \\
\text { image }\end{array}$ & $\mathrm{MRI}$ & 97 & 41 & 80 & 8 & 17 & 33 & 10 radiomic features \\
\hline $\begin{array}{l}\text { Qiao,2020 } \\
(24)\end{array}$ & Retrospective & China & 267 & $\begin{array}{l}\text { Conventional } \\
\text { algorithm }\end{array}$ & $\begin{array}{l}\text { Functional } \\
\text { image }\end{array}$ & $\mathrm{MRI}$ & 136 & 131 & 115 & 25 & 21 & 106 & 246 radiomic features \\
\hline $\begin{array}{l}\text { XY Zhou,2020 } \\
\text { (30) }\end{array}$ & Retrospective & China & 228 & $\begin{array}{l}\text { Conventional } \\
\text { algorithm }\end{array}$ & $\begin{array}{l}\text { Functional } \\
\text { image }\end{array}$ & $\mathrm{MRI}$ & 158 & 70 & 149 & 5 & 9 & 65 & 9 radiomic features \\
\hline $\begin{array}{l}\text { Zhou,2020 } \\
\text { (29) }\end{array}$ & Retrospective & China & 227 & Deep learning & $\begin{array}{l}\text { Functional } \\
\text { image }\end{array}$ & $\mathrm{MRI}$ & $\begin{array}{l}91 \\
48\end{array}$ & $\begin{array}{l}62 \\
26\end{array}$ & $\begin{array}{l}83 \\
41\end{array}$ & $\begin{array}{c}17 \\
9\end{array}$ & $\begin{array}{l}8 \\
7\end{array}$ & $\begin{array}{l}45 \\
17\end{array}$ & $\begin{array}{l}1 \text { Clinical and } 5 \text { radiomics } \\
\text { features }\end{array}$ \\
\hline $\begin{array}{l}\text { Sakai,2020 } \\
\text { (25) }\end{array}$ & Retrospective & $\begin{array}{l}\text { Japan } \\
+ \text { USA }\end{array}$ & 24 & Machine learning & $\begin{array}{l}\text { Conventional } \\
\text { image }\end{array}$ & MMG & 31 & 20 & 21 & 5 & 10 & 15 & 6 radiomic features \\
\hline
\end{tabular}

MMG, Mammography; US, Ultrasound; MRI, Magnetic Resonance Imaging; BC, Breast cancer; TP, True positive; FP, False positive; TN, True negative; FN, False negative. 

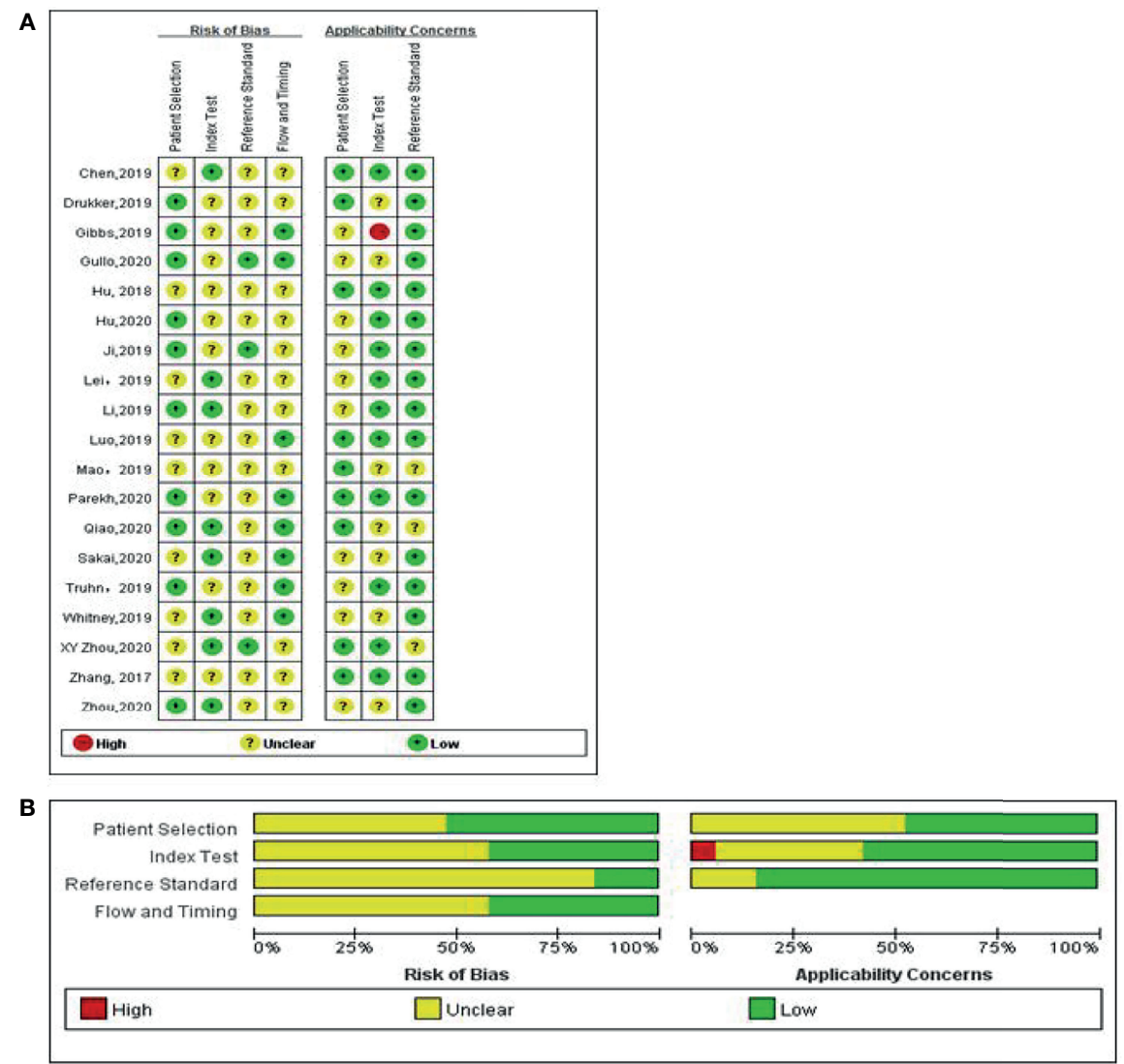

FIGURE 2 | Methodological quality of the studies included in the meta-analysis according to the QUADAS 2 tool for risk of bias and applicability concerns. Green, yellow, and red circles represent low, unclear, and high risk of bias, respectively. (A) Individual studies, (B) summary.
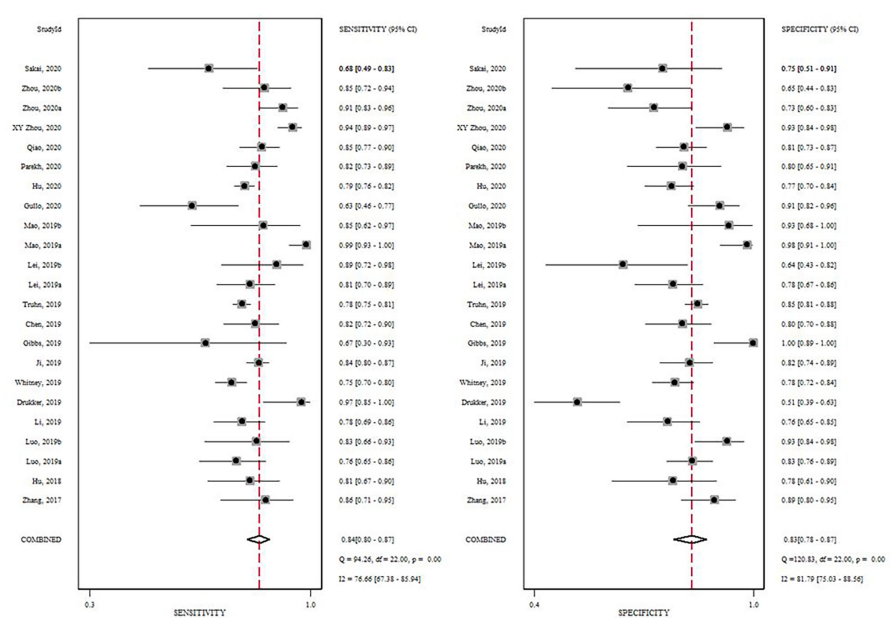

FIGURE 3 | Forrest plot of the effect size calculated as log odds ratio for 19 studies investigating the diagnostic accuracy of radiomics in the differentiation of BC from breast masses. Numbers are pooled estimates, with 95\% confidence intervals (Cls) depicted with horizontal lines. Heterogeneity statistics are shown at bottom right. 


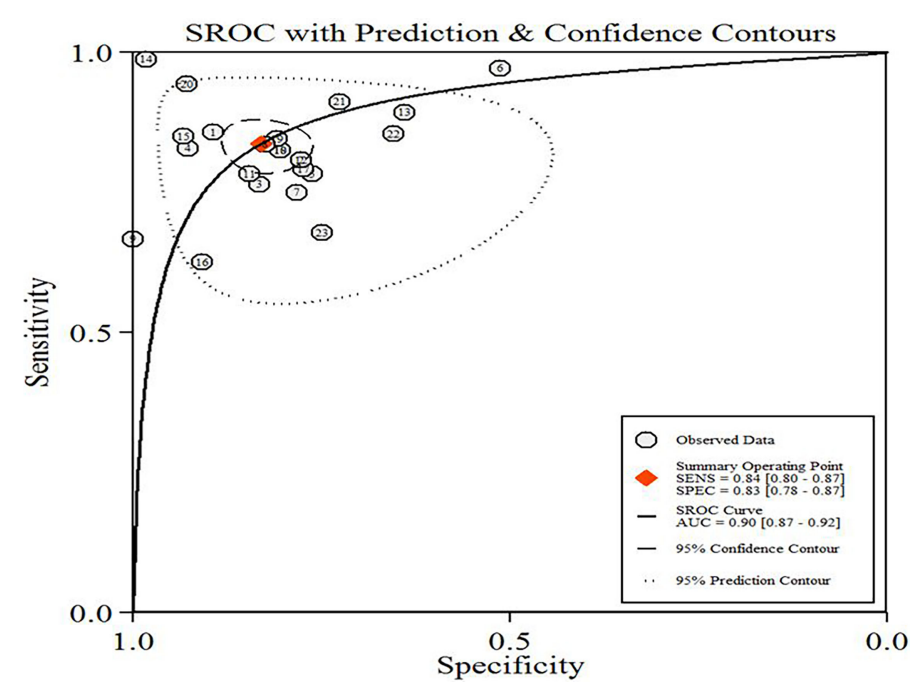

FIGURE 4 | Hierarchical summary receiver operating characteristic curve (SROC) plot of diagnostic performance in predicting BC of the included radiomic models. The numbers in circles correspond to the order of the articles in Table $\mathbf{1 .}$

after removing studies of adjusted unreported variables did not change our findings (Table 3 ).

\section{DISCUSSION}

We compared the preoperative predictive value of radiomics in the diagnostic performance of BC in different studies. The results showed that the diagnostic value of radiomics was high in predicting $\mathrm{BC}$ with an aggregated sensitivity, specificity, and AUC of $0.84,0.83$, and 0.91 , respectively. Although the number and types of features varied among the 19 included studies, which may influence the aggregated sensitivity and specificity, radiomics was shown to have good predictive ability of BC in each study. Significant heterogeneity was identified in our study. Specifically, the screening methods, selection of the scanner manufacturer and model, acquisition methods, and reconstruction parameters were shown to contribute to the heterogeneity in imaging data.

Sensitivity analyses showed that our results were reliable and stable after each study was sequentially removed, and the unreported adjusted variables were omitted.

The specificity and AUC of conventional and functional imaging analyses were similar, but conventional imaging had a

TABLE 2 | Subgroup analyses.

\begin{tabular}{|c|c|c|c|c|c|c|}
\hline Subgroup & Number of study & Sensitivity & Specificity & PLR & NLR & AUC \\
\hline \multicolumn{7}{|l|}{ Imaging modality } \\
\hline MMG & 6 & 0.87 & 0.79 & 4.2 & 0.16 & 0.91 \\
\hline US & 5 & 0.82 & 0.87 & 6.2 & 0.21 & 0.9 \\
\hline \multicolumn{7}{|l|}{ Study Design } \\
\hline Prospective & 1 & 0.97 & 0.51 & 2.2 & 0.44 & 0.84 \\
\hline China & 10 & 0.86 & 0.85 & 5.7 & 0.16 & 0.92 \\
\hline USA & 8 & 0.77 & 0.8 & 3.9 & 0.28 & 0.85 \\
\hline \multicolumn{7}{|l|}{ Imaging technique } \\
\hline Conventional image & 6 & 0.88 & 0.82 & 4.9 & 0.15 & 0.92 \\
\hline Functional image & 13 & 0.82 & 0.83 & 4.9 & 0.22 & 0.9 \\
\hline \multicolumn{7}{|l|}{ Modeling methods } \\
\hline
\end{tabular}

MMG, Mammography; US, Ultrasound; MRI, Magnetic Resonance Imaging; AUC, Area under curve; PLR, Positive likelihood ratio; NLR, Negative likelihood ratio. 
TABLE 3 | Sensitivity analyses.

\begin{tabular}{|c|c|c|c|c|c|}
\hline Study removed & Sensitivity & Specificity & PLR & NLR & AUC \\
\hline No & 0.84 & 0.83 & 4.9 & 0.2 & 0.9 \\
\hline Zhang, 2017 (28) & 0.84 & 0.83 & 4.8 & 0.2 & 0.9 \\
\hline $\mathrm{Hu}, 2018$ (15) & 0.84 & 0.83 & 5 & 0.19 & 0.9 \\
\hline Luo, 2019 (21) & 0.84 & 0.82 & 4.8 & 0.19 & 0.9 \\
\hline Li, 2019 (19) & 0.84 & 0.83 & 5 & 0.19 & 0.9 \\
\hline Drukker, 2019 (13) & 0.83 & 0.84 & 5.2 & 0.2 & 0.9 \\
\hline Whitney, 2019 (27) & 0.84 & 0.83 & 5 & 0.19 & 0.9 \\
\hline Ji, 2019 (17) & 0.84 & 0.83 & 5 & 0.2 & 0.9 \\
\hline Gibbs, 2019 (14) & 0.84 & 0.82 & 4.7 & 0.2 & 0.9 \\
\hline Chen, 2019 (12) & 0.84 & 0.83 & 5 & 0.19 & 0.9 \\
\hline Truhn, 2019 (26) & 0.84 & 0.83 & 4.9 & 0.19 & 0.9 \\
\hline Lei, 2019 (18) & 0.84 & 0.84 & 5.2 & 0.19 & 0.91 \\
\hline Mao, 2019 (22) & 0.82 & 0.81 & 4.4 & 0.22 & 0.89 \\
\hline Gullo, 2020 (20) & 0.84 & 0.84 & 4.9 & 0.19 & 0.9 \\
\hline $\mathrm{Hu}, 2020$ (16) & 0.84 & 0.83 & 5 & 0.19 & 0.9 \\
\hline Parekh, 2020 (23) & 0.84 & 0.83 & 5 & 0.19 & 0.9 \\
\hline Qiao, 2020 (24) & 0.84 & 0.83 & 5 & 0.2 & 0.9 \\
\hline XY Zhou, 2020 (30) & 0.83 & 0.82 & 4.7 & 0.21 & 0.89 \\
\hline Zhou, 2020 (29) & 0.84 & 0.83 & 5.2 & 0.2 & 0.9 \\
\hline Sakai, 2020 (25) & 0.84 & 0.83 & 5 & 0.19 & 0.9 \\
\hline
\end{tabular}

AUC, Area under curve; PLR, Positive likelihood ratio; NLR, Negative likelihood ratio.

slightly higher sensitivity. A possible explanation is that conventional imaging analyses included in this meta-analysis were combined with special examination methods. Li et al. combined the radiomic analysis of breast tumors and the parenchyma to improve the diagnostic accuracy of BC (19). Luo et al. used a nomogram combined with radiomics and the Breast Imaging Reporting and Data System (BI-RADS) score to predict $\mathrm{BC}(21)$. As for imaging modalities, the sensitivity and AUC of predicting BC by MMG were slightly higher than those of MRI and US, but the specificity was slightly lower. The use of new ultrasound imaging techniques, such as ultrasound elastography and contrast-enhanced ultrasound, may improve the detection of BC. Multi-modal MRI imaging techniques can detect most early-stage BCs, and the specificity of MRI is usually higher than that of MMG and US (31). In terms of modeling methods, ML and DL were widely studied, among which support vector machines and convolutional neural networks were the most commonly used. Logistic regression was also applied because the status of the breast mass (BC or non-BC) is a dichotomous variable. The results showed that radiomics based on either modeling method could achieve high diagnostic efficiency in predicting BC. Lastly, different data sources and study designs influenced the aggregated sensitivity, specificity, and AUC. Thus, more studies focusing on these subgroups are needed.

The preoperative diagnosis and clinical staging of $\mathrm{BC}$ are implemented mainly through the visual observation and analysis of medical images. The BI-RADS (32) score is a standardized description of imaging features of breast tumors, and it provides an approximate risk of malignancy to a lesion but lacks a characteristic evaluation of the intrinsic heterogeneity in tumors reflecting different biological behaviors of BC. To overcome limitations in the observation of tumor images by the naked eye, artificial intelligence has been increasingly applied to the mining and use of medical image data to meet the growing need for individualized evaluation (33). With the indepth study of radiomics, models based on radiomics features have been shown to be a promising non-invasive method for BC classification and prediction (34). Reportedly, radiomics models based on features extracted from preoperative MMG, US, or MRI images had a relatively high predictive performance (12-30). Texture feature analysis based on US sonoelastography was first used to propose a quantitative radiomics approach for the feature selection and classification of breast tumors (28). Subsequently, many studies performed feature extraction from multi-parameter MRI images, including T2-weighted (T2w) MRI sequences, diffusionweighted imaging (DWI) sequences, and dynamic contrastenhanced (DCE)-MRI sequences, and constructed wellperformed radiomics predictive models using $\mathrm{ML}$ or DL methods $(12,15,16,20,23,24,26,29,30)$. A recent study suggested that mammography radiomics combined with quantitative three-compartment breast image analysis could reduce unnecessary breast biopsies (13).

Our meta-analysis of preoperative BC prediction using radiomics methods has two advantages. First, to the best of our knowledge, this study involving 19 articles and 5865 breast masses is the first meta-analysis to assess the diagnostic efficacy of radiomics models in predicting BC before surgery. Secondly, this study evaluated the diagnostic efficacy of radiomics models in predicting $\mathrm{BC}$ by comparing imaging modalities, modeling methods, and other subgroups, thereby providing ideas for subsequent radiomics research.

There are several inherent limitations to this study that need to be discussed. First, the methodology of radiomics studies included in this analysis was different as different medical centers use various examination equipment, and the selection of imaging modality, feature extraction, and modeling methods provides an 
infinite number of combinations. Second, the code used for feature extraction and model building was not publicly available for any of the 19 studies included in this analysis, preventing replication and independent validation of the research results. Third, because our study used summary statistics rather than individual raw data, it was not possible to achieve more reliable results. However, it was possible to achieve more precise delineation and control potential residual confounding, a common limitation of meta-analyses.

\section{CONCLUSIONS}

Our study shows that radiomics models based on preoperative imaging features are useful for the prediction of $\mathrm{BC}$ and have high diagnostic efficacy and consistency among studies. Radiomics is expected to provide a new quantitative diagnostic method for clinical work, but more well-designed prospective radiomics trials are needed to demonstrate its effectiveness and ability to translate into clinical practice.

\section{REFERENCES}

1. Cancer Tomorrow. International Agency for Research on Cancer . Available at: $\mathrm{http}: / /$ gco.iarc.fr/tomorrow/graphicisotype?type $=0$ \&population $=900 \&$ mode $=$ population $\&$ sex $=2 \&$ cancer $=39 \&$ age_group $=$ value $\& a p c \_$male $=0 \& a p c \_$ female $=0$ (Accessed January 5, 2020).

2. Gillies RJ, Kinahan PE, Hricak H. Radiomics: Images Are More Than Pictures, They are Data. Radiology (2016) 278:563-77. doi: 10.1148/radiol.2015151169

3. Weind KL, Maier CF, Rutt BK, Moussa M. Invasive Carcinomas and Fibroadenomas of the Breast: Comparison of Microvessel DistributionsImplications for Imaging Modalities. Radiology (1998) 208(2):477-83. doi: 10.1148/radiology.208.2.9680579

4. Cerussi A, Shah N, Hsiang D, Durkin A, Butler J, Tromberg BJ. In Vivo Absorption, Scattering, and Physiologic Properties of 58 Malignant Breast Tumors Determined by Broadband Diffuse Optical Spectroscopy. J BioMed Opt (2006) 11(4):044005. doi: 10.1117/1.2337546

5. Valdora F, Houssami N, Rossi F, Calabrese M, Tagliafico AS. Rapid Review: Radiomics and Breast Cancer. Breast Cancer Res Treat (2018) 169(2):217-29. doi: 10.1007/s10549-018-4675-4

6. Bickelhaupt S, Paech D, Kickingereder P, Steudle F, Lederer W, Daniel H, et al. Prediction of Malignancy by a Radiomic Signature From Contrast Agent-Free Diffusion MRI in Suspicious Breast Lesions Found on Screening Mammography. J Magn Reson Imaging (2017) 46(2):604-16. doi: 10.1002/jmri.25606

7. Shimauchi A, Ota H, Machida Y, Yoshida T, Satani N, Mori N, et al. Morphology Evaluation of Nonmass Enhancement on Breast MRI: Effect of a Three-Step Interpretation Model for Readers' Performances and Biopsy Recommendations. Eur J Radiol (2016) 85(2):480-8. doi: 10.1016/j.ejrad.2015.11.043

8. Whiting PF, Rutjes AW, Westwood ME, Mallett S, Deeks JJ, Reitsma JB, et al. QUADAS-2: A Revised Tool for the Quality Assessment of Diagnostic Accuracy Studies. Ann Intern Med (2011) 155:529-36. doi: 10.7326/00034819-155-8-201110180-00009

9. Moses LE, Shapiro D, Littenberg B. Combining Independent Studies of a Diagnostic Test Into a Summary ROC Curve: Data-Analytic Approaches and Some Additional Considerations. Stat Med (1993) 12:1293-316. doi: 10.1002/ sim. 4780121403

10. Swets JA. Measuring the Accuracy of Diagnostic Systems. Science (1988) 240 (4857):1285-93. doi: 10.1126/science.3287615

11. Golpe R, Jiménez A, Carpizo R, Cifrian JM. Utility of Home Oximetry as a Screening Test for Patients With Moderate to Severe Symptoms of Obstructive Sleep Apnea. Sleep (1999) 22(7):932-7.

\section{DATA AVAILABILITY STATEMENT}

The original contributions presented in the study are included in the article/supplementary material. Further inquiries can be directed to the corresponding author.

\section{AUTHOR CONTRIBUTIONS}

Guarantor of the integrity of the study: HS. Study concepts: JY. Literature research: ZL. Data acquisition: HD and YW. Data analysis: DL and ZL. Statistical analysis: HS and FZ. Manuscript preparation: ZL and YC. Manuscript editing: ZL and YC. Manuscript review: DL, HS, and JY.

\section{ACKNOWLEDGMENTS}

The authors gratefully acknowledge HS for his assistance in study design and statistical analyses.

12. Chen S, Guan X, Shu Z, Li Y, Cao W, Dong F, et al. A New Application of Multimodality Radiomics Improves Diagnostic Accuracy of Nonpalpable Breast Lesions in Patients With Microcalcifications-Only in Mammography. Med Sci Monit (2019) 25:9786-93. doi: 10.12659/MSM.918721

13. Drukker K, Giger ML, Joe BN, Kerlikowske K, Greenwood H, Drukteinis JS, et al. Combined Benefit of Quantitative Three-Compartment Breast Image Analysis and Mammography Radiomics in the Classification of Breast Masses in a Clinical Data Set. Radiology (2019) 290(3):621-8. doi: 10.1148/ radiol.2018180608

14. Gibbs P, Onishi N, Sadinski M, Gallagher KM, Hughes M, Martinez DF, et al. Characterization of Sub-1 Cm Breast Lesions Using Radiomics Analysis. J Magnet Resonance Imaging (2019) 50(5):1468-77. doi: 10.1002/jmri.26732

15. Hu B, Xu K, Zhang Z, Chai R, Li S, Zhang L. A Radiomic Nomogram Based on an Apparent Diffusion Coefficient Map for Differential Diagnosis of Suspicious Breast Findings. Chin J Cancer Res (2018) 30(4):432-8. doi: $10.21147 /$ j.issn.1000-9604.2018.04.06

16. Hu Q, Whitney HM, Giger ML. Radiomics Methodology for Breast Cancer Diagnosis Using Multiparametric Magnetic Resonance Imaging. J Med Imaging (Bellingham) (2020) 7(4):44502. doi: 10.1117/1.JMI.7.4.044502

17. Ji Y, Li H, Edwards AV, Papaioannou J, Ma W, Liu P, et al. Independent Validation of Machine Learning in Diagnosing Breast Cancer on Magnetic Resonance Imaging Within a Single Institution. Cancer Imaging (2019) 19 (1):64. doi: 10.1186/s40644-019-0252-2

18. Lei C, Wei W, Liu Z, Xiong Q, Yang C, Yang M, et al. Mammography-Based Radiomic Analysis for Predicting Benign BI-RADS Category 4 Calcifications. Eur J Radiol (2019) 121:108711. doi: 10.1016/j.ejrad.2019.108711

19. Li H, Mendel KR, Lan L, Sheth D, Giger ML. Digital Mammography in Breast Cancer: Additive Value of Radiomics of Breast Parenchyma. Radiology (2019) 291(1):15-20. doi: 10.1148/radiol.2019181113

20. Lo Gullo R, Daimiel I, Rossi Saccarelli C, Bitencourt A, Gibbs P, Fox MJ, et al. Improved Characterization of Sub-Centimeter Enhancing Breast Masses on MRI With Radiomics and Machine Learning in BRCA Mutation Carriers. Eur Radiol (2020). doi: 10.1007/s00330-020-06991-7

21. Luo W-q, Huang Q-x, Huang X-w, Hu H-t, Zeng F-q, Wang W. Predicting Breast Cancer in Breast Imaging Reporting and Data System (BI-RADS) Ultrasound Category 4 or 5 Lesions: A Nomogram Combining Radiomics and BI-RADS. Sci Rep (2019) 9(1):6721-31. doi: 10.1038/s41598-019-48488-4

22. Mao N, Yin P, Wang Q, Liu M, Dong J, Zhang X, et al. Added Value of Radiomics on Mammography for Breast Cancer Diagnosis: A Feasibility Study. J Am Coll Radiol (2019) 16(4):485-91. doi: 10.1016/j.jacr.2018.09.041 
23. Parekh VS, Jacobs MA. Multiparametric Radiomics Methods for Breast Cancer Tissue Characterization Using Radiological Imaging. Breast Cancer Res Treat (2020) 180(2):407-21. doi: 10.1007/s10549-020-05533-5

24. Qiao M, Li C, Suo S, Cheng F, Hua J, Xue D, et al. Breast DCE-MRI Radiomics: A Robust Computer-Aided System Based on Reproducible BIRADS Features Across the Influence of Datasets Bias and Segmentation Methods. Int J Comput Assist Radiol Surg (2020) 15(6):921-30. doi: 10.1007/s11548-020-02177-0

25. Sakai A, Onishi Y, Matsui M, Adachi H, Teramoto A, Saito K, et al. A Method for the Automated Classification of Benign and Malignant Masses on Digital Breast Tomosynthesis Images Using Machine Learning and Radiomic Features. Radiol Phys Technol (2019) 13(1):27-36. doi: 10.1007/s12194-019-00543-5

26. Truhn D, Schrading S, Haarburger C, Schneider H, Merhof D, Kuhl C. Radiomic Versus Convolutional Neural Networks Analysis for Classification of Contrast-Enhancing Lesions at Multiparametric Breast MRI. Radiology (2019) 290(2):290-7. doi: 10.1148/radiol.2018181352

27. Whitney HM, Taylor NS, Drukker K, Edwards AV, Papaioannou J, Schacht D, et al. Additive Benefit of Radiomics Over Size Alone in the Distinction Between Benign Lesions and Luminal A Cancers on a Large Clinical Breast MRI Dataset. Acad Radiol (2019) 26(2):202-9. doi: 10.1016/j.acra.2018.04.019

28. Zhang Q, Xiao Y, Suo J, Shi J, Yu J, Guo Y, et al. Sonoelastomics for Breast Tumor Classification: A Radiomics Approach With Clustering-Based Feature Selection on Sonoelastography. Ultrasound Med Biol (2017) 43(5):1058-69. doi: 10.1016/j.ultrasmedbio.2016.12.016

29. Zhou J, Zhang Y, Chang KT, Lee KE, Wang O, Li J, et al. Diagnosis of Benign and Malignant Breast Lesions on DCE-MRI by Using Radiomics and Deep Learning With Consideration of Peritumor Tissue. J Magn Reson Imaging (2020) 51(3):798-809. doi: 10.1002/jmri.26981

30. Zhou X, Gao F, Duan S, Zhang L, Liu Y, Zhou J, et al. Radiomic Features of Pk-DCE MRI Parameters Based on the Extensive Tofts Model in Application of Breast Cancer. Phys Eng Sci Med (2020) 43(2):517-24. doi: 10.1007/s13246020-00852-9
31. Kuhl CK, Schrading S, Leutner CC, Morakkabati-Spitz N, Wardelmann E, Fimmers R, et al. Mammography, Breast Ultrasound, and Magnetic Resonance Imaging for Surveillance of Women at High Familial Risk for Breast Cancer. J Clin Oncol (2005) 23(33):8469-76. doi: 10.1200/ JCO.2004.00.4960

32. Rao AA, Feneis J, Lalonde C, Ojeda-Fournier H. A Pictorial Review of Changes in the BI-RADS Fifth Edition. Radiographics (2016) 36(3):623-39. doi: $10.1148 / \mathrm{rg} .2016150178$

33. Lambin P, Leijenaar RTH, Deist TM, Peerlings J, de Jong EEC, van Timmeren J, et al. Radiomics: The Bridge Between Medical Imaging and Personalized Medicine. Nat Rev Clin Oncol (2017) 14(12):749-62. doi: 10.1038/ nrclinonc.2017.141

34. Conti A, Duggento A, Indovina I, Guerrisi M, Toschi N. Radiomics in Breast Cancer Classification and PredictionSemin Cancer Biol. Semin Cancer Biol (2021) 72:238-50. doi: 10.1016/ j.semcancer. 2020.04.002

Conflict of Interest: The authors declare that the research was conducted in the absence of any commercial or financial relationships that could be construed as a potential conflict of interest.

Publisher's Note: All claims expressed in this article are solely those of the authors and do not necessarily represent those of their affiliated organizations, or those of the publisher, the editors and the reviewers. Any product that may be evaluated in this article, or claim that may be made by its manufacturer, is not guaranteed or endorsed by the publisher.

Copyright (C) $2022 \mathrm{Li}, \mathrm{Ye}, \mathrm{Du}$, Cao, Wang, Liu, Zhu and Shen. This is an open-access article distributed under the terms of the Creative Commons Attribution License (CC BY). The use, distribution or reproduction in other forums is permitted, provided the original author(s) and the copyright owner(s) are credited and that the original publication in this journal is cited, in accordance with accepted academic practice. No use, distribution or reproduction is permitted which does not comply with these terms. 